Research Article

\title{
Dynamic Response of Railway Bridges under Heavy-Haul Freight Trains
}

\author{
Ye Xiao $\mathbb{D}^{1,2}$ Xiaoyong Luo $\mathbb{D}^{1},{ }^{1}$ Jinhong Liu $\mathbb{D}{ }^{1}$ and Kun Wang $\mathbb{D}^{1}$ \\ ${ }^{1}$ School of Civil Engineering, Central South University, Changsha 410075, China \\ ${ }^{2}$ School of Civil and Architectural Engineering, East China University of Technology, Nanchang 330013, China
}

Correspondence should be addressed to Xiaoyong Luo; csu-luoxy@csu.edu.cn

Received 21 June 2019; Accepted 21 January 2020; Published 10 March 2020

Academic Editor: Carlo Rainieri

Copyright (c) 2020 Ye Xiao et al. This is an open access article distributed under the Creative Commons Attribution License, which permits unrestricted use, distribution, and reproduction in any medium, provided the original work is properly cited.

In the freight railway bridge, the increase of the train running speed and train axle loads can enlarge dynamic response (DR) of the railway bridges, which leads to excessive vibration of bridges and endangers the structural safety. In this paper, a threedimensional coupled finite element (FE) model of a heavy-haul freight train-track-bridge (HHFTTB) is established using multibody dynamics theory and FE method, and the DR for the coupled system of HHFTTB are solved by ABAQUS/Explicit dynamic analysis method. The field-measured data for a $32 \mathrm{~m}$ simply supported prestressed concrete beam of a heavy-haul railway in China are analyzed, and the validity of the FE model is verified. Finally, the effects of train formation number, train running speed, and train axle loads on DR of the heavy-haul railway bridge structures are studied. The results show that increasing the train formation number only has an influence on DR duration of the bridge structure, rather than the peak value of DR, when the train formation number exceeds a certain number; besides, the train axle loads and train running speed have significant influence on DR of the bridge structure. The results of this study can be used as reference for the design of heavy-haul railway bridges and the reinforcement transformation of existing railway bridges.

\section{Introduction}

With its substantial cargo transportation capacity, significant economic and social benefits, development of railway heavy-haul transportation has become important in almost every country around the world [1]. However, due to the rapid development of society, there is still a contradiction between transportation capacity and transportation volume. In order to alleviate the railway transportation pressure, the upgrading of existing railway infrastructure has received increasing attention. Due to the increase of heavy-haul train speed, axle load and traction quality, the structural reliability of existing bridges in terms of impact coefficient, fatigue life, and dynamic response (DR) will be reduced [2, 3]. Assessing the impact of heavy-haul trains on existing railway bridges is an important part of the railway industry to maintain safe and reliable transport services.

Vibration of bridge structure occurs when heavy-haul train passes through the bridge. This vibration may cause the fatigue damage and durability damage of bridge structure, affecting the safety and stability of train on the railway bridge and even causing derailment, which can lead to serious casualties for the train. In the wake of development in heavy-haul and high-speed railways over the world, the problems of train-bridge dynamic interaction have become increasingly prominent, and considerable progress has been made in this field over the recent decades. Most researchers used field tests and numerical simulations to investigate the vehicle-bridge dynamic interaction [4-9]. Numerical models such as moving load models $[10,11]$ and dynamic interaction models [12-18] have been developed for the train-bridge system (TBS) dynamic interaction. Zhang et al. $[19,20]$ created the dynamic interaction model of a TBS by using finite element (FE) method and calculated the DR of a prestressed concrete box girder bridge. Neves et al. [21] presented a direct algorithm to analyze the vehicle-structure interaction, and the accuracy of the method was validated using a numerical example. Antolín et al. 
[22-24] proposed a coupled dynamic model of high-speed TBS based on the nonlinear wheel-rail force and calculated and analyzed the DR of the vehicle-bridge system. Yu and Mao [25] presented a random wheel-rail force model based on MATLAB and random theory to analyze the probability analysis of high-speed railway TBS. Li et al. [26] proposed a direct stiffness method for the strain analysis of a steel bridge based on the vehicle-bridge coupled dynamic system. An existing steel bridge and a simply supported concrete bridge were taken as an example to validate the reliability of the method. Galvín et al. [27] analyzed the DR for a special short span of high-speed bridge commonly used in Spain by using two FE models and predicted the vertical vibration level of the bridge. Gou et al. [28] conducted a field test and numerical analysis on a continuous girder bridge to investigate the dynamic effects of high-speed trains operation on the bridges. Zhang et al. [29] received reliable prediction on the train-bridge interactions of the a steel double-deck bridge using a 3D FE model with parallel explicit FE modeling. Zhai et al. [30] used another 3D finite element model to investigate the dynamic interaction model of highspeed TBS and proposed a method to analyze and assess the ride comfort and operating safety of trains passing through the bridges.

However, the current researches were mostly focused on DR of the bridges for the high-speed trains, while there were few studies on the bridges for the heavy-haul trains. The main objects of the previous analysis were mostly focused on the acceleration and displacement response of bridges, while study on the strain response of bridges was rare. In addition, there were few reports regarding the effect of train formation on DR of the bridge structures. Therefore, a 3D coupling FE model of the heavy-haul freight train-track-bridge (HHFTTB) system considering wheel-rail contact relationship is established, based on a simply supported prestressed concrete beam which is commonly used for Chinese railway bridges. The acceleration, displacement, and strain response of the bridge for heavy-haul freight trains are analyzed and compared with the field test results. The effects of the freight train formation number, axle load, and running speed on DR of the bridges are studied. The results are significant for the safety operation and maintenance of bridges and provide important information and basis for the design of new heavyhaul railway bridges and the reinforcement transformation of existing railway bridges.

\section{Train-Track-Bridge Dynamic Coupling System}

\subsection{Train Model}

2.1.1. Description. At present, C64K, C70A, and C80 are the three main types of freight trains running on Chinese heavyhaul railway lines, and the corresponding axle loads are $21 \mathrm{t}$, $23 \mathrm{t}$, and $25 \mathrm{t}$, respectively. C80 was selected as the object of research in this study, which is shown in Figure 1. The main technical parameters of a C80 heavy-haul freight train are as listed in Table 1.
2.1.2. Numerical Model. To simplify the analysis, the assumptions are considered in the modeling of the heavy-haul freight train (HHFT) as follows. (a) The moving HHFT are composed of several identical freight trains; each freight train is regarded as a multi-rigid-body system consisting of one car body, four wheel sets, two bogies, primary suspensions system, and secondary suspensions system. (b) The car body, bogies, and wheel sets in each freight train are regarded as the rigid elements, ignoring their elastic deformation in vibration. (c) Each car body and bogie have five degrees of freedom (DOFs), that is, $\left(Y_{c i}, Y_{t i} ; Z_{c i}, Z_{t i} ; \varphi_{c i}, \varphi_{t i}\right.$; $\left.\theta_{c i}, \theta_{t i} ; \psi_{c i}, \psi_{t i}\right)$ the lateral, vertical, pitching, rolling, and yawing, respectively. The wheel sets have three DOFs, including $\left(Y_{w i}, Z_{w i}, \theta_{w i}\right)$ the lateral, vertical, and rolling. Therefore, each freight train element has 27 DOFs, and the simplified freight train dynamic model is shown in Figure 2.

Based on the above assumptions, the dynamics equation of the freight train is described as follows:

$$
M_{c} \ddot{u}_{c}+C_{c} \dot{u}_{c}+K_{c} u_{c}=F_{c} \text {, }
$$

where $M_{c}, C_{c}$, and $K_{c}$ are mass matrix, damping matrix, and stiffness matrix of the freight car, respectively; $u_{c}, \dot{u}_{c}$, and $\ddot{u}_{c}$ are the displacement, velocity, and acceleration vectors of the freight car, respectively; $F_{c}$ expresses the force vector.

The numerical model of the HHFT is created using a simplified 3D FE model developed in ABAQUS software [31]. In this model, the car body, bogies, and wheel sets are modeled by rigid-body element; the primary and secondary suspension devices between the car body and the bogies and wheel sets and bogies are modeled by linear spring damping elements, and the stiffness and damping parameters of suspensions are obtained in Table 1. Figure 3 shows the numerical model of the HHFT.

2.2. Ballasted Track-Bridge Model. Most of the heavy-haul railways are with ballasted tracks in China. In this paper, the Nanpaihe bridge on Shuo-Huang heavy-haul railway line is taken as the object of research, and the FE model of the ballasted track-bridge was built up. The Nanpaihe bridge is an 18-span prestressed simply supported concrete T-beam with a total length of $576 \mathrm{~m}(18 \times 32 \mathrm{~m})$, which is one of the most common types in the Shuo-Huang heavy-haul railway lines. Reinforced concrete piers with circular end plates bored pile foundation are used in the bridge. The piers 4, 5, and 6 are located in the main channel. The outline and the mid-span section of the Nanpaihe bridge are as shown in Figure 4.

To validate the reliability of the track-bridge model, a simply supported beam is selected as the research object and the FE model of a ballasted track-bridge is created by using ABAQUS software. Solid elements are used to simulate the rail in order to calculate the wheel-rail contact relationship accurately with the elastic modulus being $210 \mathrm{GPa}$, the density being $7.8 \mathrm{tf} / \mathrm{m}^{3}$, and Poisson's ratio being 0.3 . The sleeper and ballast are both simulated by solid elements with the elastic modulus being $36.5 \mathrm{GPa}$ and $11.0 \mathrm{GPa}$, the density being $2.5 \mathrm{tf} / \mathrm{m}^{3}$ and $2.0 \mathrm{tf} / \mathrm{m}^{3}$, and Poisson's ratio being 0.2 and 0.27 , respectively. Beam and diaphragm are also 


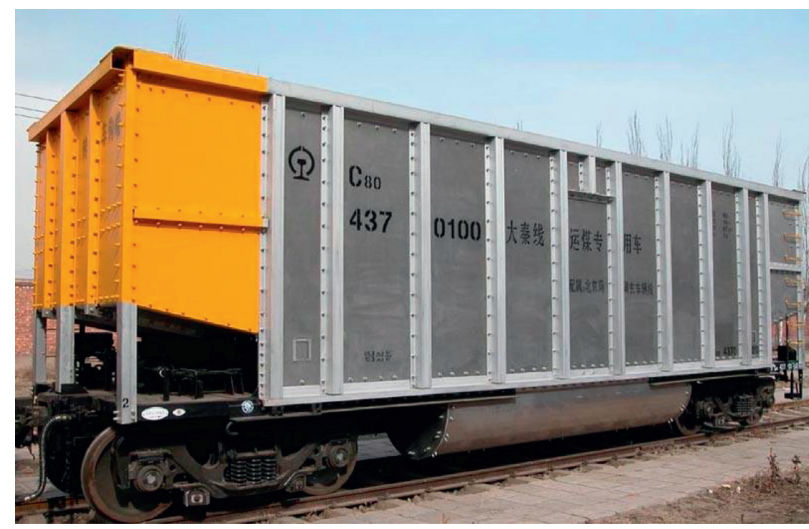

(a)

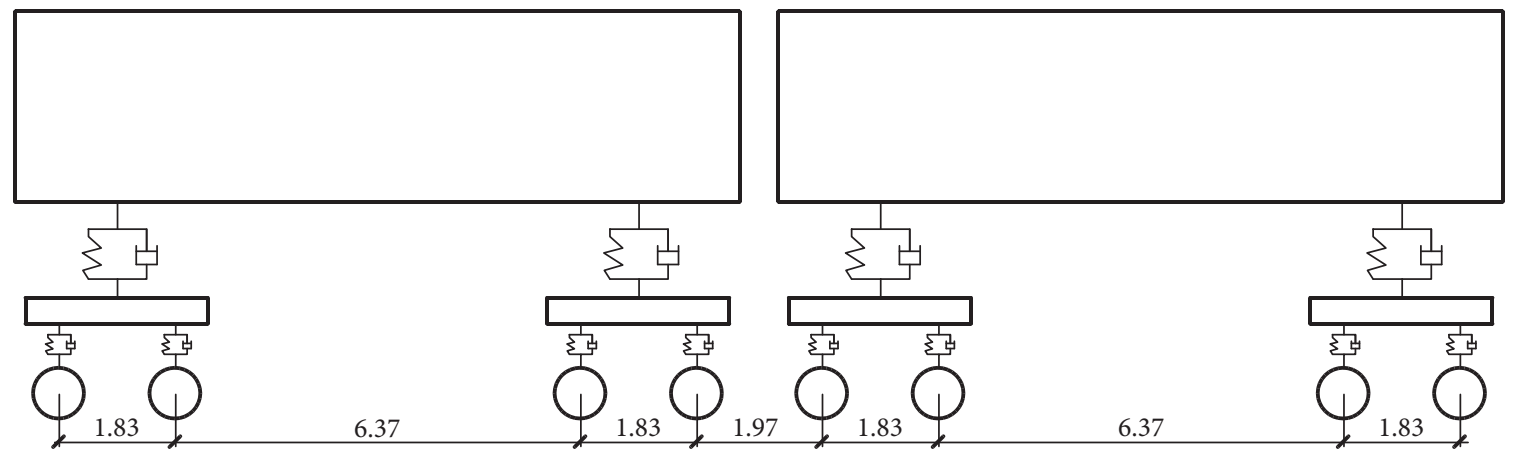

(b)

Figure 1: Heavy-haul freight train (C80): (a) photograph; (b) freight train wheelbase (unit: m).

TABle 1: Parameters of C80 freight car.

\begin{tabular}{lcc}
\hline Parameters & Unit & Value \\
\hline Mass of the car body & $\mathrm{kg}$ & 90297 \\
Mass of the wheel set & $\mathrm{kg}$ & 497 \\
Mass of the bogy & $\mathrm{kg}$ & 1171 \\
Vertical stiffness of primary suspension & $\mathrm{MN} / \mathrm{m}$ & 160 \\
Lateral stiffness of primary suspension & $\mathrm{MN} / \mathrm{m}$ & 11 \\
Vertical damping of primary suspension & $\mathrm{kN} \cdot \mathrm{s} / \mathrm{m}$ & 4 \\
Lateral damping of primary suspension & $\mathrm{kN} \cdot \mathrm{s} / \mathrm{m}$ & 4 \\
Vertical stiffness of secondary suspension & $\mathrm{MN} / \mathrm{m}$ & 4.235 \\
Lateral stiffness of secondary suspension & $\mathrm{MN} / \mathrm{m}$ & 3.127 \\
Vertical damping of secondary suspension & $\mathrm{kN} \cdot \mathrm{s} / \mathrm{m}$ & 3 \\
Lateral damping of secondary suspension & $\mathrm{kN} \cdot \mathrm{s} / \mathrm{m}$ & 3 \\
\hline
\end{tabular}

simulated by solid elements, with the elastic modulus of $35.5 \mathrm{GPa}$, the density of $2.5 \mathrm{tf} / \mathrm{m}^{3}$ and the Poisson's ratio of 0.2 . Linear spring damping elements are used to simulate the damping and stiffness properties of rail fasteners and cushion plates. The sleeper and ballast and ballast and bridge are connected by binding. Figure 5 presents the 3D FE model of track-bridge.

The vibration modes of the bridge girder is calculated by the modal analysis with ABAQUS software. The first six natural frequencies and corresponding mode shapes of the bridge girder are shown in Figure 6. The modal analysis results illustrate that the first vibration mode is the lateral vibration with the natural frequency $f_{1}=2.9 \mathrm{~Hz}$ and the second vibration mode is the vertical vibration with the corresponding frequency $f_{2}=5.62 \mathrm{~Hz}$. Table 2 presents a comparison for natural frequencies between the numerical results and the measured ones in [26]. The results illustrate a good agreement between them with the relative differences smaller than $5 \%$, which validates the accuracy of the bridge model.

2.3. Wheel-Rail Contact Model. The wheel-rail contact model is the critical problem of train-bridge dynamic interaction. In ABAQUS, the wheel-rail contact relationship is modeled by surface-to-surface contact type, and it is critical to identify the master and the slave surfaces in the contact pair to prevent mesh intrusion. Since the wheel is a rigid body, the master surface of the wheel-rail contact pair is the wheel surface, while the slave surface is the top surface of the rail based on the principle of the masterslave surface. The wheel-rail contact relationship is as shown in Figure 7.

Hertz nonlinear elastic contact theory [30] and dynamic friction model [32] are adopted to simulate the wheel-rail normal contact and tangential contact, respectively. Therefore, the wheel-rail normal force is expressed by

$$
P(t)=\left[\frac{1}{G} \delta Z(t)\right]^{3 / 2},
$$

where $G$ is the contact constant of wheel-rail which is expressed as follows: 


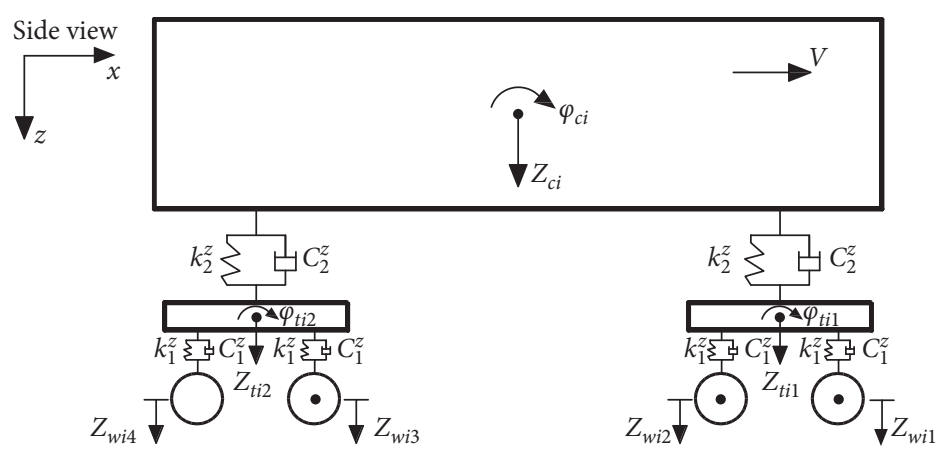

(a)

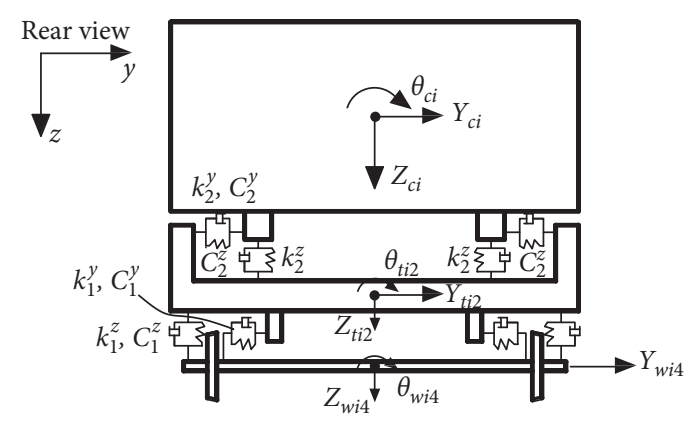

(b)

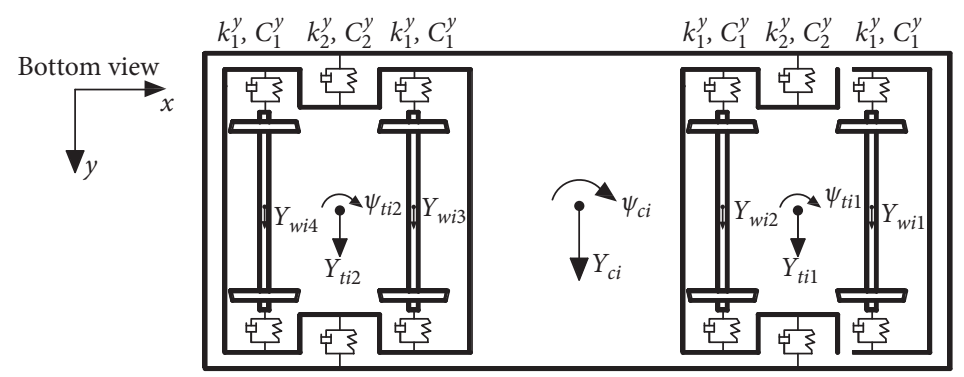

(c)

Figure 2: Dynamic model of freight train element.

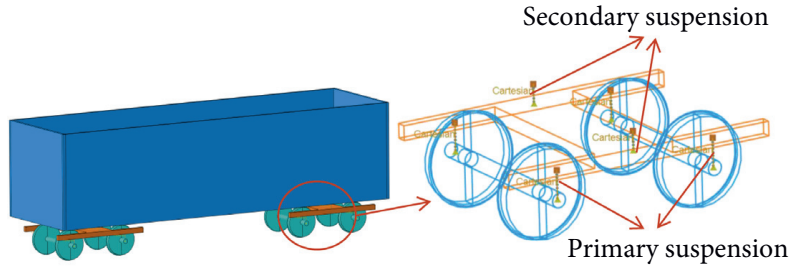

FIGURE 3: Numerical model of the heavy-haul freight train.

$$
G=3.86 R^{-0.115} \times 10^{-8}\left(\frac{m}{N^{2 / 3}}\right),
$$

where $R$ is the wheel radius $(\mathrm{m}) ; \delta Z(t)$ represents the elastic compression displacement, which is given as follows:

$$
\delta Z(t)=Z_{2}(t)-Z_{1}(t)-Z_{0}(t)
$$

where $Z_{1}(t), Z_{2}(t)$, and $Z_{0}(t)$ represent the rail displacement, the wheel displacement, and the irregularity of wheelrail displacement, respectively.

The tangential contact forces of wheel-rail are described by the dynamic friction model, which is written as

$$
F=\mu P(t)
$$

where $F$ is the tangential contact force; $\mu$ represent the friction coefficient between wheels and rails, which is written as

$$
\mu=\mu_{k}+\left(\mu_{s}-\mu_{k}\right) e^{-d_{c} v_{e}},
$$

where $\mu_{k}, \mu_{s}, d_{c}$ and $v_{e}$ represent the dynamic friction coefficient, static friction coefficient, attenuation coefficient and relative sliding rate between wheel and rail, respectively.
2.4. Track Irregularities. As there is no track spectrum standard for characterizing the status of heavy-haul railway lines in China, the Class 5 spectrum suggested by the US Federal Railroad Administration is used to simulate the track irregularities in this paper $[3,18]$.

$$
\left\{\begin{array}{l}
S_{v}(\Omega)=\frac{k A_{v} \Omega_{c}^{2}}{\Omega^{2}\left(\Omega^{2}+\Omega_{c}^{2}\right)}, \\
S_{h}(\Omega)=\frac{k A_{h} \Omega_{c}^{2}}{\Omega^{2}\left(\Omega^{2}+\Omega_{c}^{2}\right)},
\end{array}\right.
$$

where $S_{v}(\Omega)$ and $S_{h}(\Omega)$ are vertical and lateral irregularities, respectively; the units are $\mathrm{cm}^{2} /(\mathrm{rad} / \mathrm{m}) ; \Omega$ and $\Omega_{c}$ represent the spatial angular frequencies and the cut-off frequencies, respectively; the units both are $\mathrm{rad} / \mathrm{m} ; A_{v}$ and $A_{h}$ are surface roughness constants, with the units being $\left(\mathrm{cm}^{2} \mathrm{rad} / \mathrm{m}\right)$. Values of $\Omega_{c}, A_{v}$, and $A_{h}$ are equal to $0.8245,0.2095$, and 0.0762 , respectively; $k$ is a parameter which is assumed as 0.25 .

The amplitude and phase of the spectrum were obtained according to the power spectrum of the track irregularities, and then the power spectrum of track irregularity was transformed into time domain samples by inverse Fourier transform method [33]. The simulation results of track irregularity samples were obtained using MATLAB software as shown in Figure 8, in which the train running speed is $80 \mathrm{~km} / \mathrm{h}$.

2.5. The Solving Process of the Model. Consequently, the solving procedures of the model of HHFTTB coupled DR system is summarized as shown in Figure 9. The DR for 


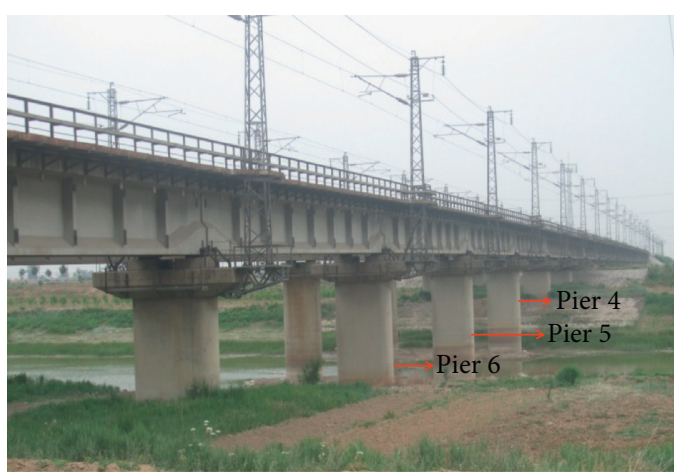

(a)

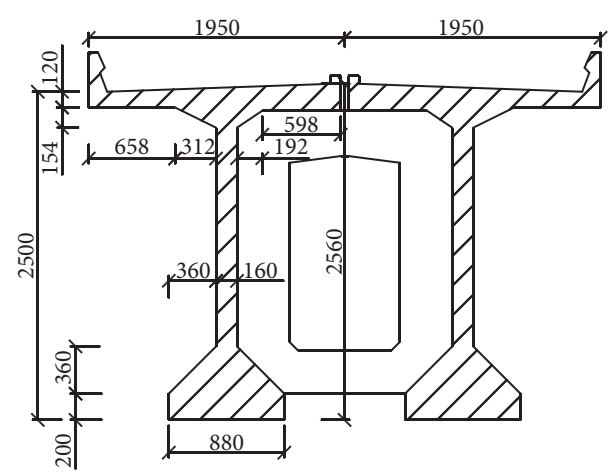

(b)

Figure 4: The $32 \mathrm{~m}$ prestressed concrete simply supported bridge. (a) View of the Nanpaihe Bridge. (b) Mid-span cross section (unit: mm).

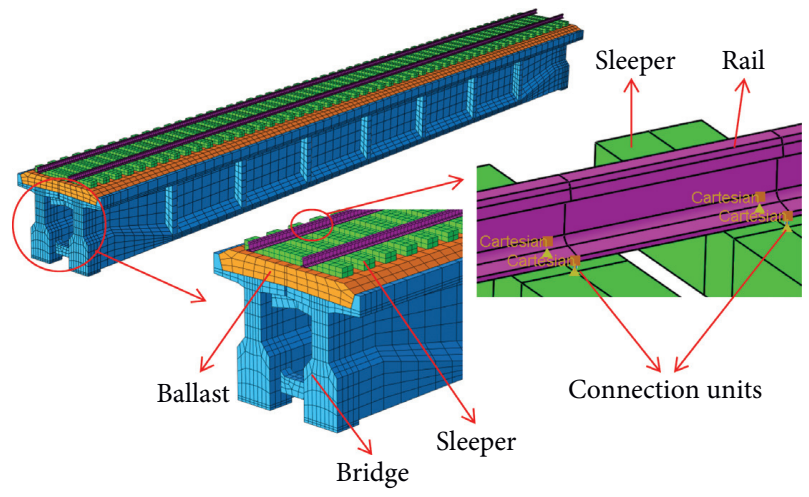

FIGURE 5: 3D FE model of track-bridge.

bridges under the heavy-haul freight trains can be obtained using the flowchart of Figure 9.

\section{Validation of the HHFTTB Coupling Dynamic System}

To obtain the dynamic performance of the bridge and to validate the HHFTTB FE model, a field test on the Nanpaihe bridge was carried out on April 6-13, 2016. The sensors were located at the bridge girders' mid-span section of the second and the third spans, which is shown in Figure 10. The lateral and vertical accelerations at bridge girders' mid-span section were gauged by sensors 891-II, and the concrete strains were obtained by strain gauges. All the gauges and sensors were calibrated before the field test. The field test train consists of 108 freight trains with the train running speed range from 60 to $80 \mathrm{~km} / \mathrm{h}$, and there were 15 groups of measured data in the field test. The devices of field test were as shown in Figure 11.

Figures 12(a) and 12(b) show the measured and numerical acceleration time histories for the DR of the bridge girder's mid-span section with the train running speed of $80 \mathrm{~km} / \mathrm{h}$, which agree well with each other, and Figure 12(c) shows the measured and numerical strain time histories at bottom of the bridge girder's mid-span section. It can be seen from that the results of numerical strain have a good agreement with their measured counterparts. This suggests that the HHFTTB coupling dynamic model can correctly predict the DR of the railway bridges.

\section{Numerical Results and Discussion}

The 2nd-5th span bridge segments of Nanpaihe bridge are modeled using the proposed model. The 3D dynamic FE model of the HHFTTB is shown in Figure 13. In order to reduce the calculation cost, a train consisting of eight C80 freight trains is used in the subsequent numerical simulation. To simulate the initial state of the train before entering the bridge, it is assumed that the trains pass through the Nanpaihe bridge at a uniform speed of $80 \mathrm{~km} / \mathrm{h}$ starting from $20 \mathrm{~m}$ away from the pier. ABAQUS/Explicit dynamic analysis method is adopted to solve the DR of the HHFTTB coupled system. The effects of train formation number, train axle loads, and train running speed on DR of the Nanpaihe bridge are discussed.

4.1. Effect of the Number of Train Formations. The effect of different train formation numbers (2-8 train formations) on DR of the Nanpaihe bridge is analyzed, and the time histories for the vertical deflection and dynamic strain of the bridge girders' mid-span section (pier 2 to pier 3 ) are shown in Figure 14. Figure 15 shows the relationship between the maximum DR of the bridge girders' mid-span section and the train formation number.

Figure 14 shows that the vertical deflection and dynamic strain duration of bridges increase with the increase of train formation number. Due to the continuous excitation and vibration of train formation load, the maximum value of the vertical deflection and dynamic strain of the bridge girders' mid-span section increase slightly. Figure 15 shows the relationship between the maximum DR of the bridge girders' mid-span section and train formation. It can be seen that when the number of train formations is greater than four, the increment of the DR of the bridge girders' mid-span section is very small. When the number of train formation reaches six, the peak DR tends to be stable gradually. Therefore, the increase of the train formation number will not affect the peak DR when it exceeds six. 


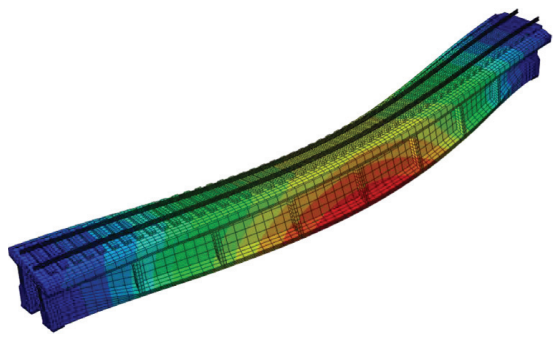

(a)

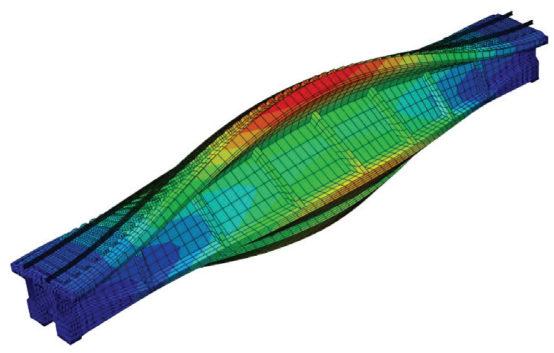

(c)

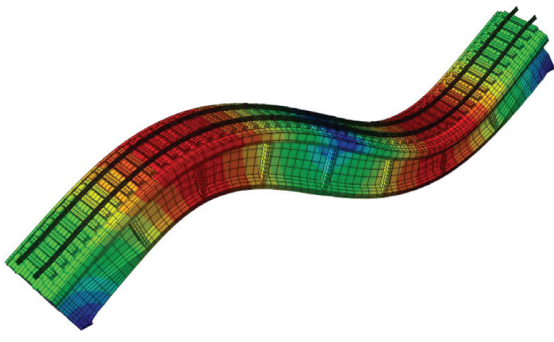

(e)

Figure 6: Vibration modes of the bridge girder. (a) $f_{1}=2.9 \mathrm{~Hz}$. (f) $f_{6}=19.87 \mathrm{~Hz}$.

TABLE 2: Natural frequencies of the bridge girder.

\begin{tabular}{lccc}
\hline \multirow{2}{*}{ Vibration modes } & \multicolumn{2}{c}{ Frequency $(\mathrm{Hz})$} & \multirow{2}{*}{ Error (\%) } \\
& Reference [26] & Numerical & \\
\hline Lateral vibration & 2.90 & 2.96 & 2.06 \\
Vertical vibration & 5.50 & 5.62 & 2.18 \\
\hline
\end{tabular}

4.2. Effect of the Train Axle Loads. The effects of train axle loads on DR of the Nanpaihe bridge are discussed, which are $25 \mathrm{t}, 27 \mathrm{t}, 30 \mathrm{t}, 32.5 \mathrm{t}, 35 \mathrm{t}, 37.5 \mathrm{t}$, and $40 \mathrm{t}$, respectively. The relationship curve between the maximum DR of the bridge girders' mid-span section and the train axle loads is as shown in Figure 16.

Figure 16 illustrates that the DR of the bridge structure is closely correlated with the axle loads of heavy-haul freight train. The vertical deflection and dynamic strain of the bridge girders' mid-span section increase with the increase of axle loads of train, the vertical acceleration and lateral acceleration of the bridge girders' mid-span section increase gradually with the increase of the axle loads of the train, and the increased amplitude is larger and larger. When the axle loads of the train vary from $25 \mathrm{t}$ to $40 \mathrm{t}$, the vertical acceleration and lateral acceleration rise more than $150 \%$.

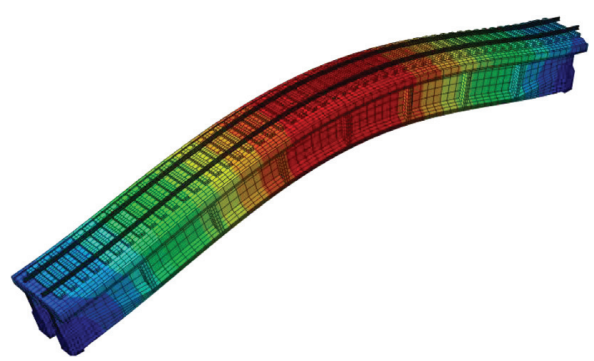

(b)

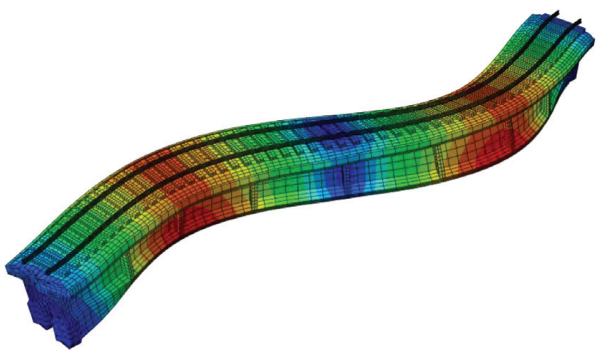

(d)

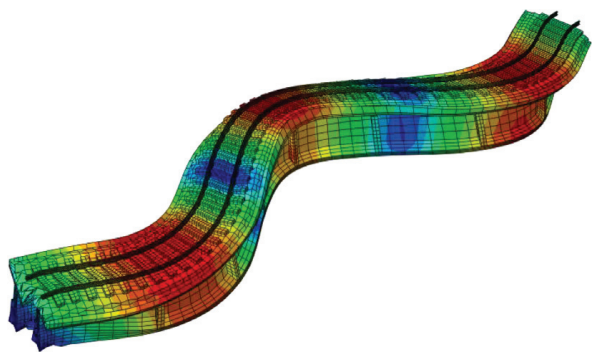

(f)

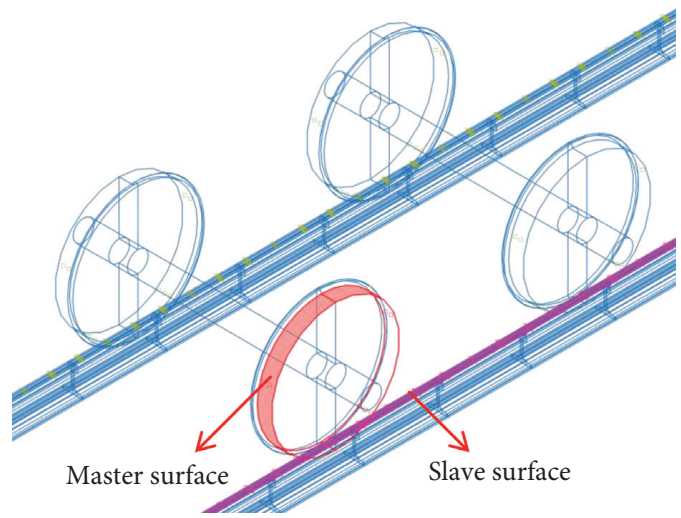

FIgURE 7: Wheel-rail contact relation.

4.3. Effect of the Train Running Speed. The increase of train running speed will boost the dynamic effect of vehicles and cause adverse effects to the tracks and bridges. It is assumed that C80 freight trains pass the bridge within the running speed range of $40 \mathrm{~km} / \mathrm{h}$ to $100 \mathrm{~km} / \mathrm{h}$ at $10 \mathrm{~km} / \mathrm{h}$ intervals. Figure 17 shows the relationship between the maximum DR of the bridge girders' mid-span section and the train running speed. 


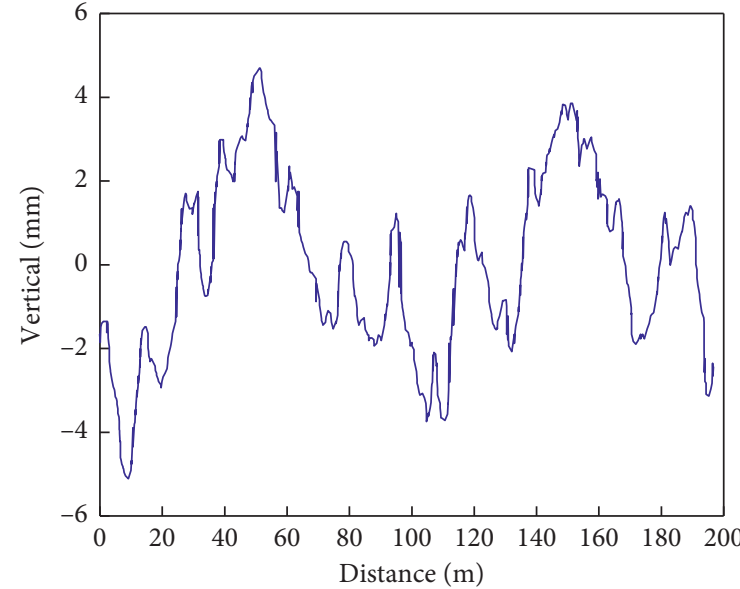

(a)

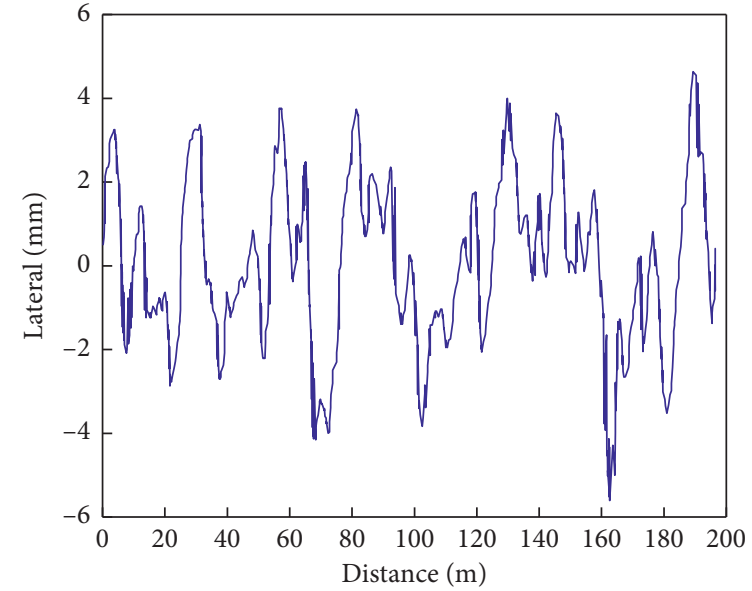

(b)

FIGURE 8: Track irregularity: (a) vertical; (b) lateral.

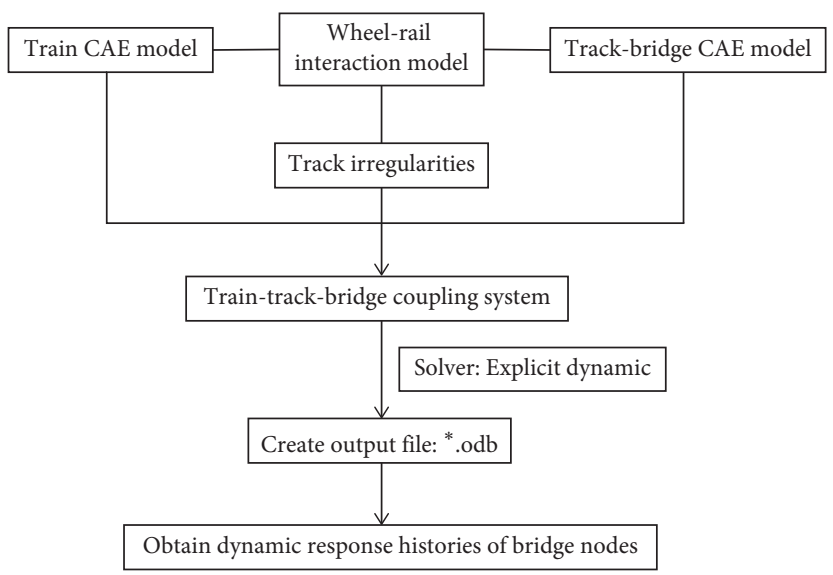

FIgURE 9: Solution procedures for DR of the bridge.

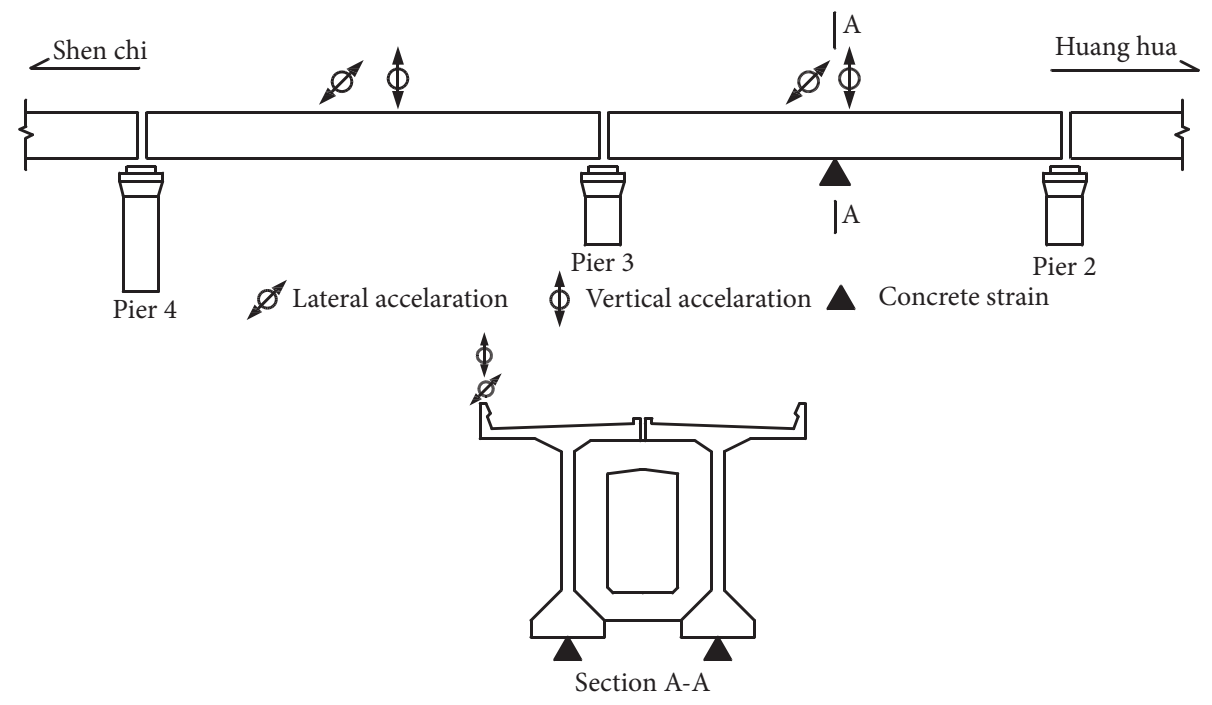

FIgURE 10: Sensors arranged on the bridge. 


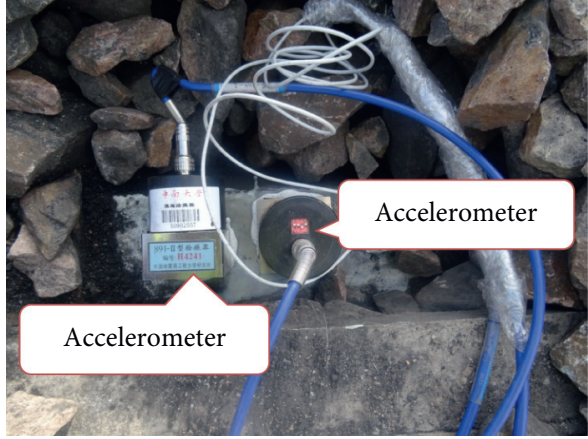

(a)

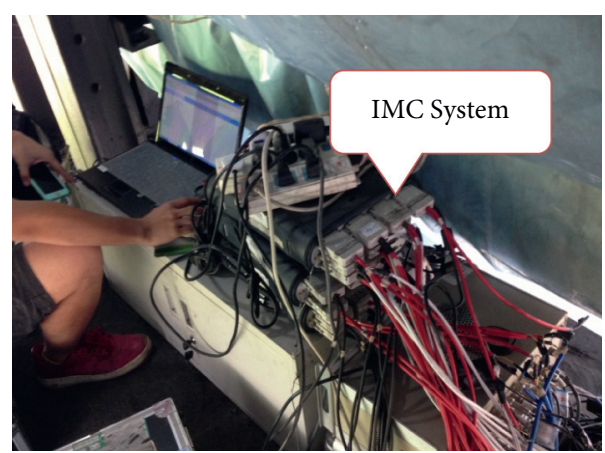

(b)

Figure 11: Measurement devices in the field test: (a) measurement of the acceleration of the bridge and (b) data acquisition system (IMC).

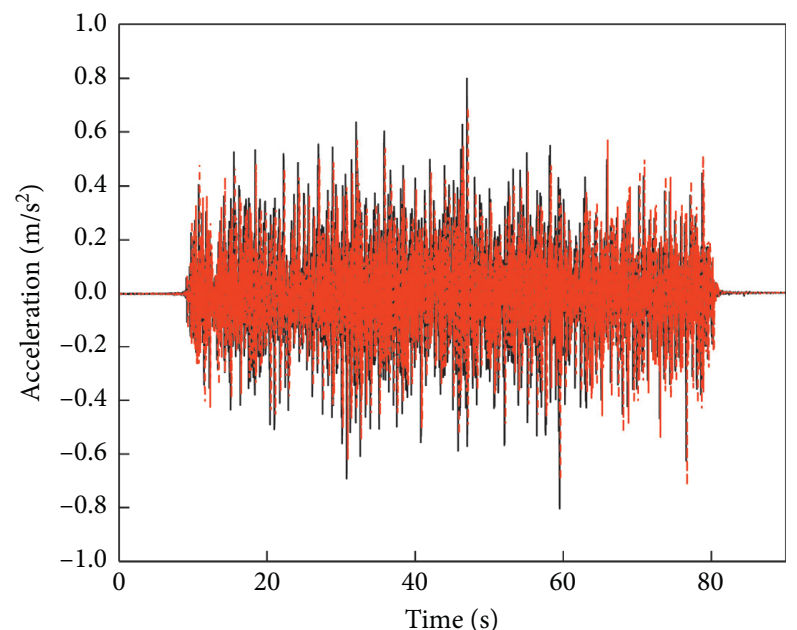

- Measured

- . - Numerical

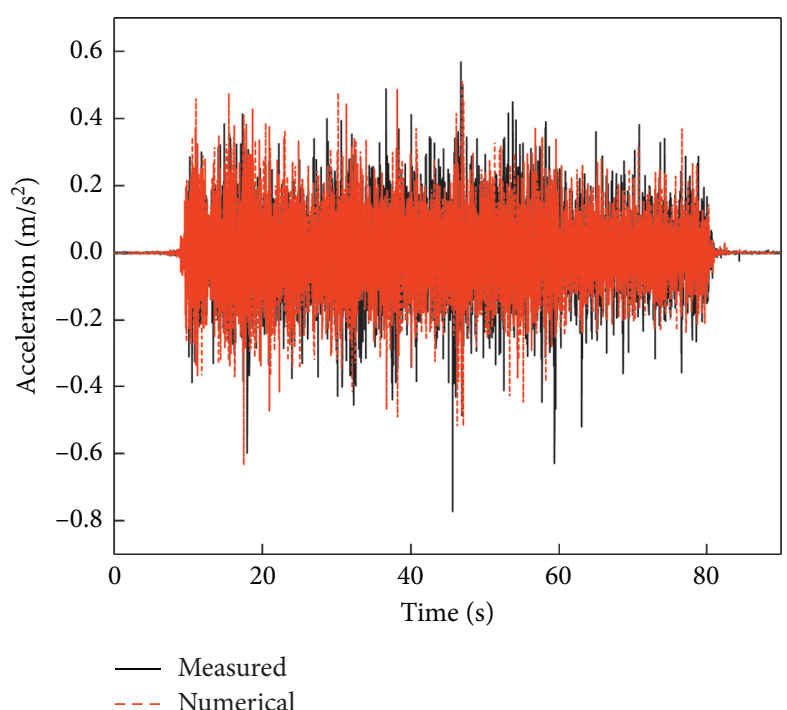

(b)

(a)

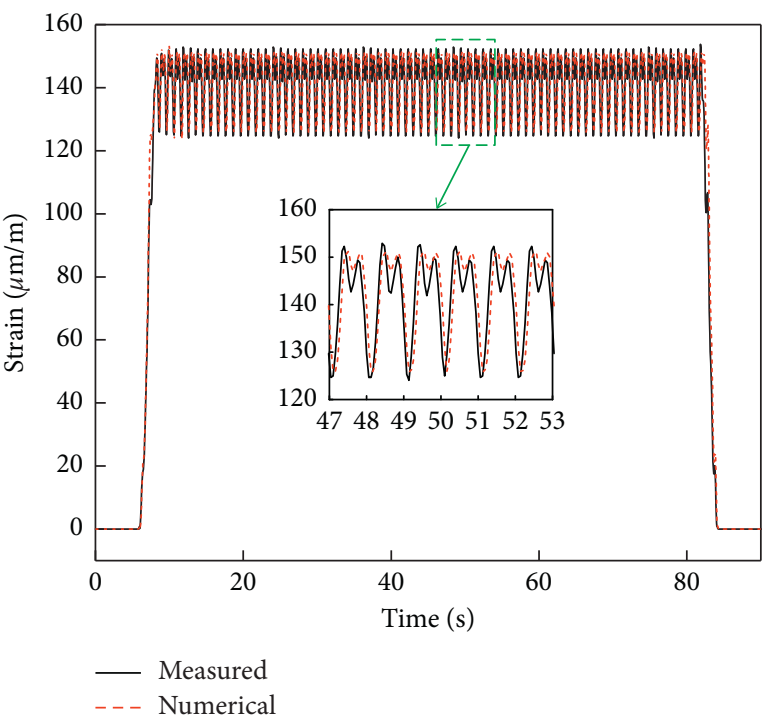

(c)

FIGURE 12: Time histories for the DR of the bridge girders' mid-span section: (a) vertical acceleration; (b) lateral acceleration; (c) strain. 


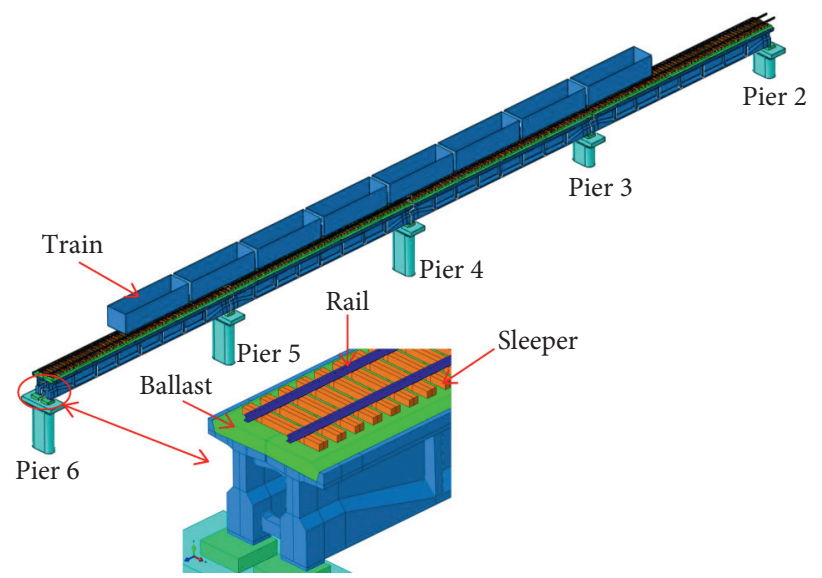

FIgURE 13: Three-dimensional coupled FE model of HHFTTB.

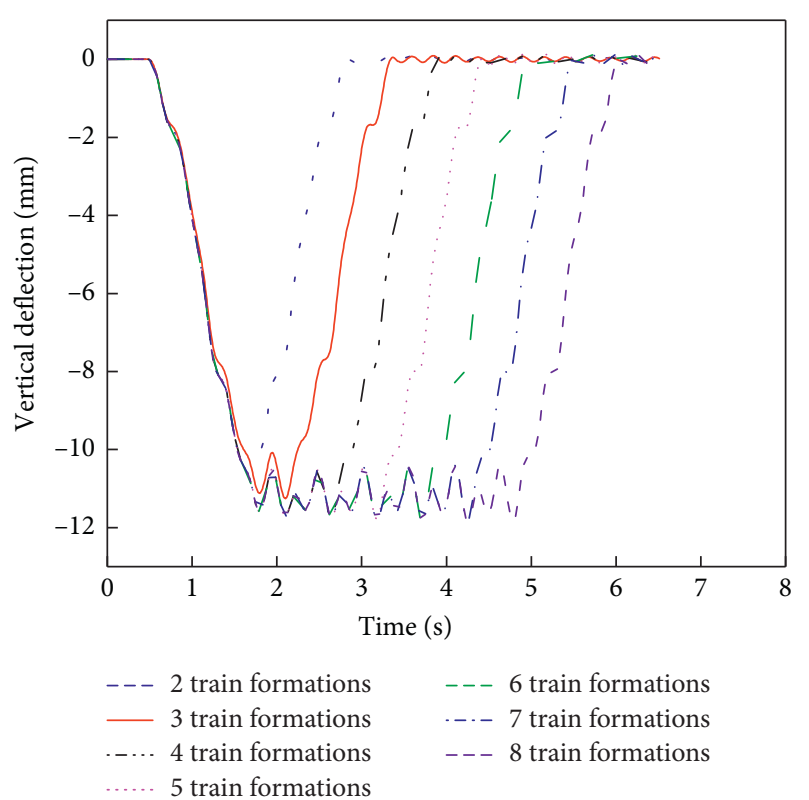

(a)

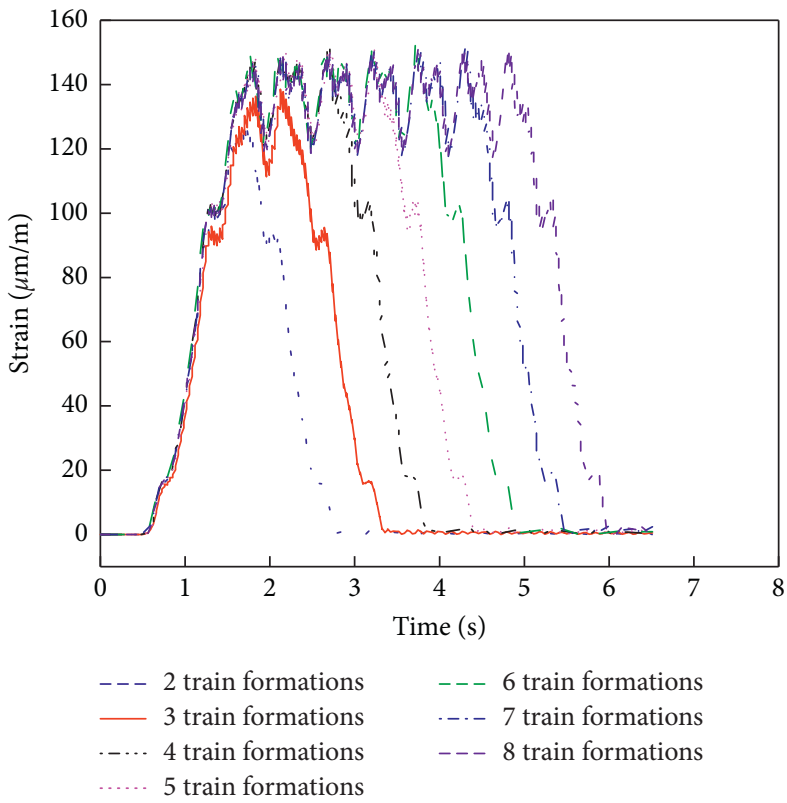

(b)

FIGURE 14: Time histories for the DR of the bridge girders' mid-span section: (a) vertical deflection; (b) strain.

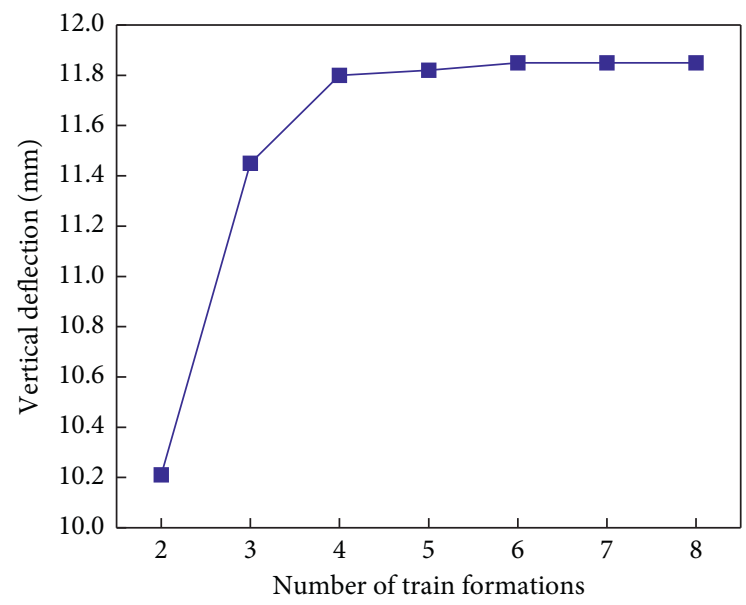

(a)

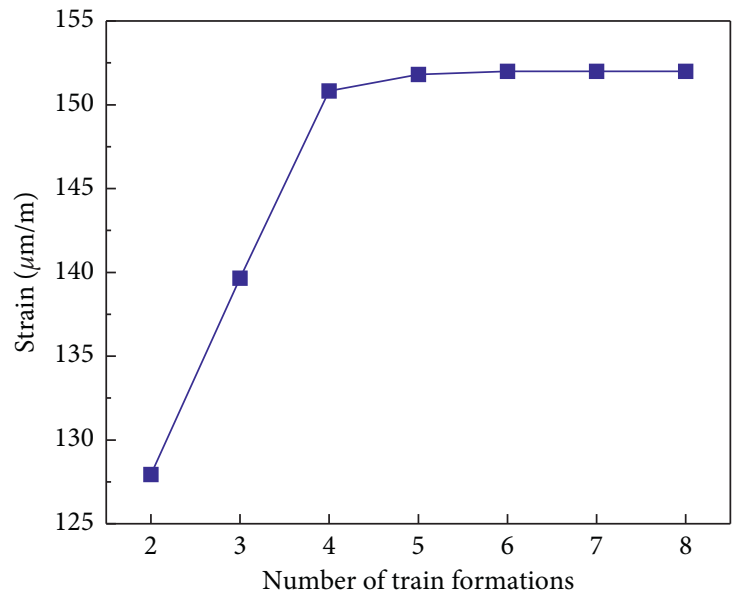

(b)

FIgURE 15: Continued. 


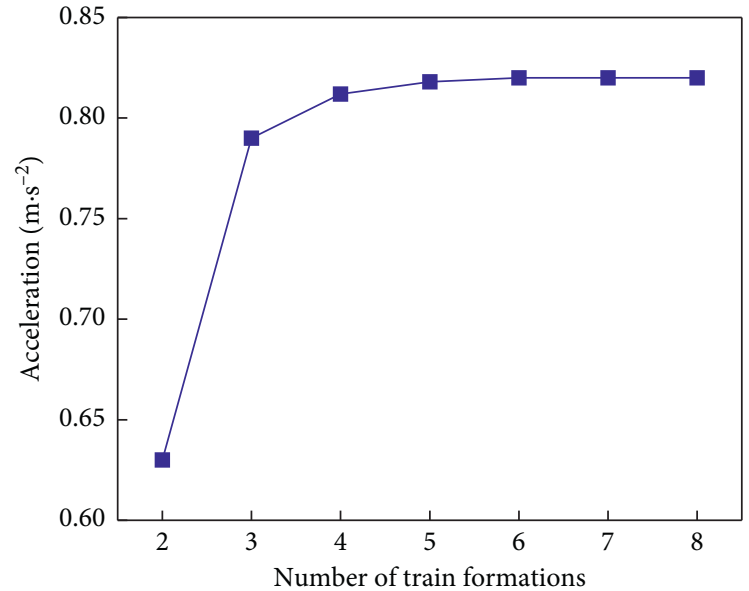

(c)

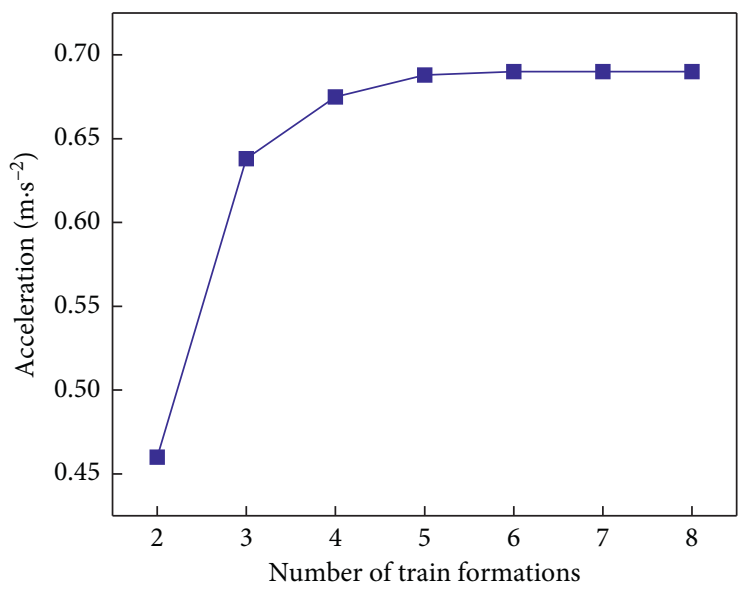

(d)

FIGURE 15: Maximum DR of the bridge girders' mid-span section with different numbers of train formations: (a) vertical deflection; (b) strain; (c) vertical acceleration; (d) lateral acceleration.

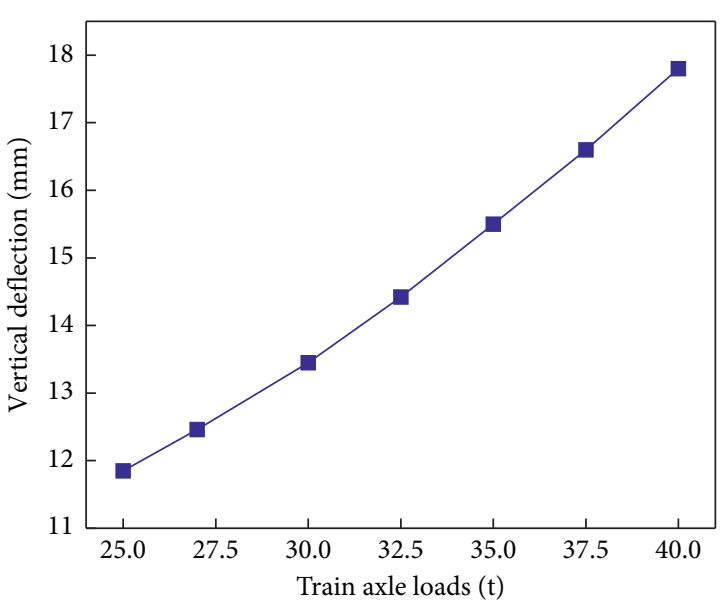

(a)

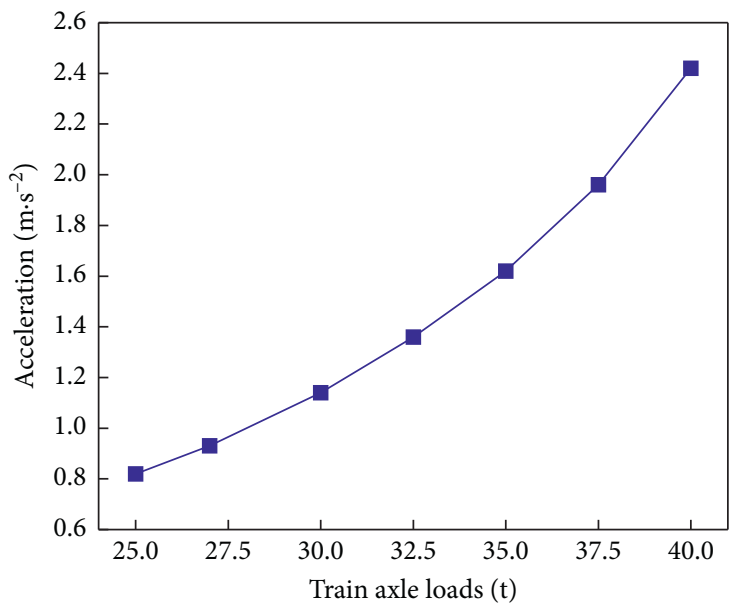

(c)

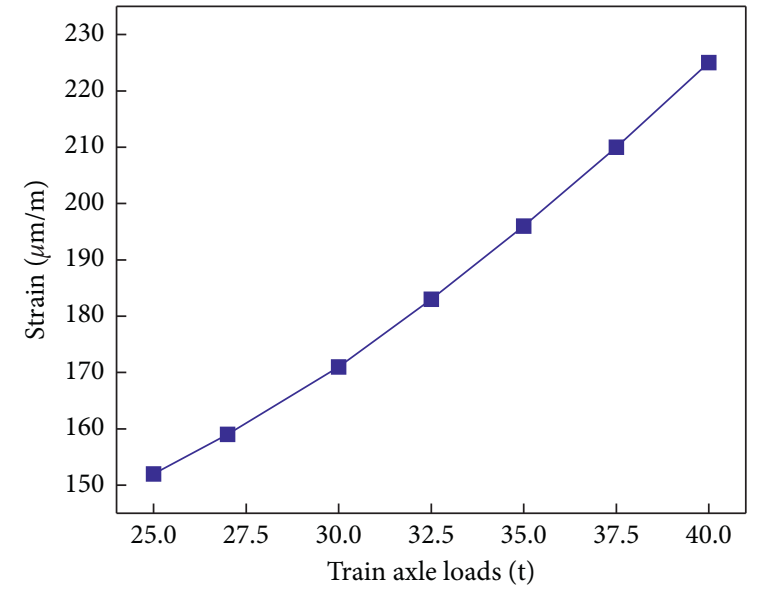

(b)

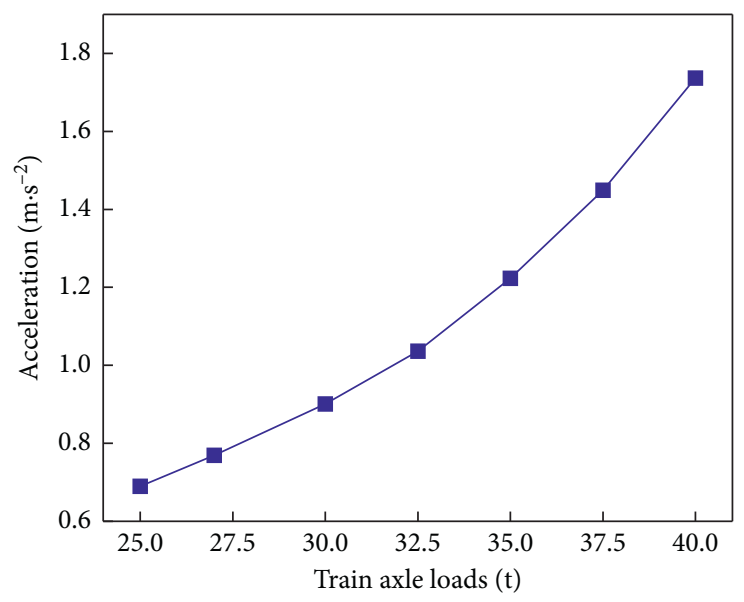

(d)

FIGURE 16: Maximum DR of the bridge girders' mid-span section with different train axle loads: (a) vertical deflection; (b) strain; (c) vertical acceleration; (d) lateral acceleration. 


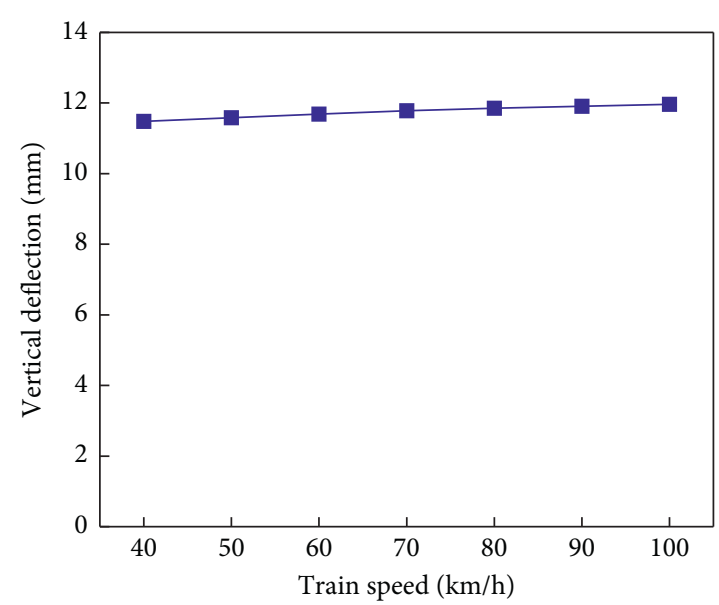

(a)

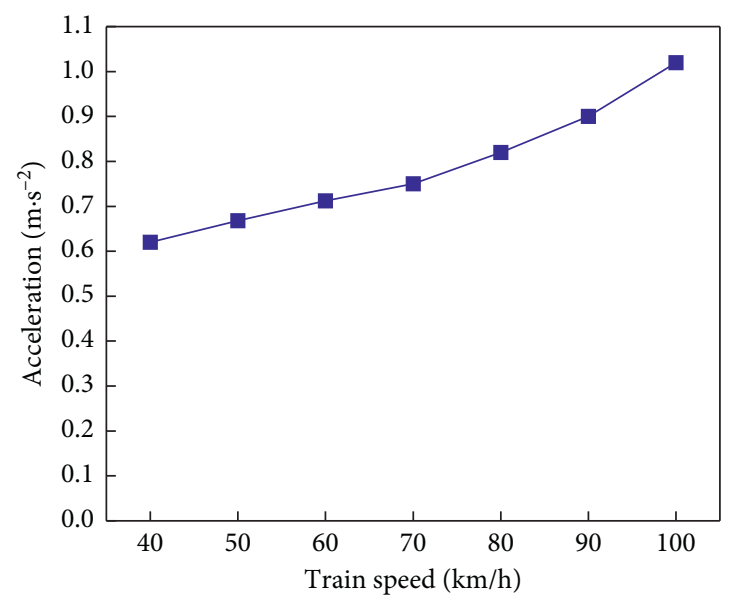

(c)

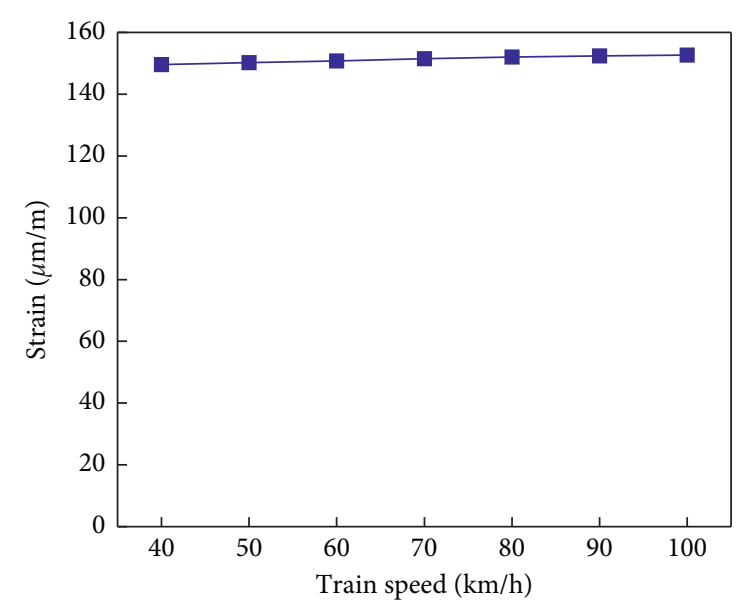

(b)

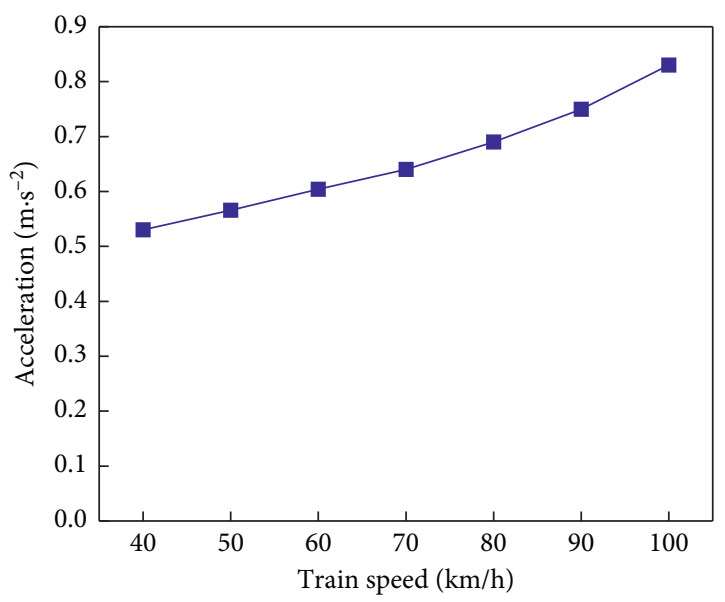

(d)

FIgURe 17: Maximum DR of the bridge girders' mid-span section with various train speeds: (a) vertical deflection; (b) strain; (c) vertical acceleration; (d) lateral acceleration.

Figure 17 shows that the increase of the train running speed enlarges the vertical deflection, dynamic strain, and vertical and lateral acceleration of the bridge girders' midspan section, while the effects on the latter two factors are much more significant than the first two. Specifically, when the train running speed increases from $40 \mathrm{~km} / \mathrm{h}$ to $100 \mathrm{~km} / \mathrm{h}$, the vertical acceleration and lateral acceleration increase to $64.51 \%$ and $56.60 \%$, respectively, while the vertical deflection and dynamic strain only increase to $4.18 \%$ and $2.07 \%$, respectively.

\section{Conclusions}

In this study, the dynamic model for the 3D coupling system of heavy-haul freight train-track-bridge is established, and the field test results of a $32 \mathrm{~m}$ simply supported prestressed concrete beam are summarized. The influences of the number of heavy-haul train formations, train axle loads, and train running speed on the DR of the railway bridge are discussed. The following primary conclusions can be drawn up.
(1) The results of numerical simulation have good agreement with the field test, which shows that the proposed FE model of heavy-haul freight traintrack-bridge is reliable.

(2) When the heavy-haul freight trains pass through a $32 \mathrm{~m}$ simply supported prestressed concrete bridge at a uniform speed and when the number of train formations is greater than four, the DR of the bridge girders' mid-span section tends to be stable. While the number of train formations exceeds six, the increase of train formation number only affects the duration of DR of the bridge structure but does not affect the peak DR. Therefore, a certain number can be assumed for the long-marshalling train when the train formation number is larger than it, to save the computation cost.

(3) The DR of a bridge structure is closely correlated with the train axle loads. The vertical deflection and dynamic strain of the bridge girders' mid-span section increase linearly with the increase of train axle loads; the vertical acceleration and lateral 
acceleration of the mid-span section of the bridge girder increase gradually with the increase of the axle loads of the train, and the increase in amplitude is larger and larger.

(4) The increase of train running speed has a certain influence on the DR of the bridge structure. The vertical deflection, dynamic strain, and acceleration at bridge girders' mid-span section increase with the increase of train running speed, while the increase in rate of the acceleration is larger than that of vertical deflection and dynamic strain.

\section{Data Availability}

The data used to support the findings of this study are available from the corresponding author upon request.

\section{Conflicts of Interest}

The authors declare there are no conflicts of interest.

\section{Acknowledgments}

This work was financially supported by the Joint Funds of the National Natural Science Foundation of China (no. U1361204), the National Natural Science Foundation of China (Grant no. 51568001), and the Science and Technology Department of Jiangxi Province (20161BBG70084).

\section{References}

[1] R. Calçada, A. Cunha, and R. Delgado, "Dynamic analysis of metallic arch railway bridge," Journal of Bridge Engineering, vol. 7, no. 4, pp. 214-222, 2002.

[2] L. R. Ticona-Melo, T. N. Bittencourt, D. Ribeiro, and R. Calçada, "Dynamic response of a railway bridge to heavy axle-load trains considering vehicle-bridge interaction," International Journal of Structural Stability and Dynamics, vol. 18 , no. 1, p. 27, 2018.

[3] Z. H. Zhu, L. D. Wang, Z. W. Yu, W. Gong, and Y. Bai, "Nonstationary random vibration analysis of railway bridges under moving heavy-haul trains," International Journal of Structural Stability and Dynamics, vol. 18, no. 3, Article ID 1850035, 21 pages, 2018.

[4] J. Wallin, J. Leander, and R. Karoumi, "Strengthening of a steel railway bridge and its impact on the dynamic response to passing trains," Engineering Structures, vol. 33, no. 2, pp. 635-646, 2011.

[5] Z. W. Chen, W. M. Zhai, and Q. Yin, "Analysis of structural stresses of tracks and vehicle dynamic response in train-trackbridge system with pier settlement," Proceedings of the Institution of Mechanical Engineers, Part F: Journal of Rail and Rapid Transit, vol. 232, no. 2, pp. 421-434, 2017.

[6] H. Xia, G. De Roeck, N. Zhang, and J. Maeck, "Experimental analysis of a high-speed railway bridge under Thalys trains," Journal of Sound and Vibration, vol. 268, no. 1, pp. 103-113, 2003.

[7] H. Xia, N. Zhang, and R. Gao, "Experimental analysis of railway bridge under high-speed trains," Journal of Sound and Vibration, vol. 282, no. 1-2, pp. 517-528, 2005.

[8] K. Liu, G. D. Roeck, and G. Lombaert, "The effect of dynamic train-bridge interaction on the bridge response during a train passage," Journal of Sound and Vibration, vol. 325, no. 1-2, pp. 240-251, 2009.

[9] H. Gou, X. Shi, W. Zhou, K. Cui, and Q. Pu, "Dynamic performance of continuous railway bridges: numerical analyses and field tests," Proceedings of the Institution of $\mathrm{Me}$ chanical Engineers, Part F: Journal of Rail and Rapid Transit, vol. 232, no. 3, pp. 936-955, 2018.

[10] L. Frýba, S. Kadečka, and O. Man, Dynamics of Railway Bridges, Thomas Telford Ltd., London, UK, 1996.

[11] M. Majka and M. Hartnett, "Dynamic response of bridges to moving trains: a study on effects of random track irregularities and bridge skewness," Computers \& Structures, vol. 87, no. 1920, pp. 1233-1252, 2009.

[12] Y. B. Yang and C. W. Lin, "“Vehicle-bridge interaction dynamics and potential applications," Journal of Sound and Vibration, vol. 284, no. 1-2, pp. 205-226, 2005.

[13] M.-K. Song, H.-C. Noh, and C.-K. Choi, "A new threedimensional finite element analysis model of high-speed train-bridge interactions," Engineering Structures, vol. 25, no. 13, pp. 1611-1626, 2003.

[14] Y.-S. Lee and S.-H. Kim, "Structural analysis of 3D high-speed train-bridge interactions for simple train load models," Vehicle System Dynamics, vol. 48, no. 2, pp. 263-281, 2010.

[15] H. Zhong, M. Yang, and Z. Gao, "Dynamic responses of prestressed bridge and vehicle through bridge-vehicle interaction analysis," Engineering Structures, vol. 87, pp. 116-125, 2015.

[16] M. Fedorova and M. V. Sivaselvan, "An algorithm for dynamic vehicle-track-structure interaction analysis for highspeed trains," Engineering Structures, vol. 148, pp. 857-877, 2017.

[17] Y.-S. Lee, S.-H. Kim, and J. Jung, "Three-dimensional finite element analysis model of high-speed train-track-bridge dynamic interactions," Advances in Structural Engineering, vol. 8, no. 5, pp. 513-528, 2005.

[18] D. Cantero and R. Karoumi, "Numerical evaluation of the mid-span assumption in the calculation of total load effects in railway bridges," Engineering Structures, vol. 107, pp. 1-8, 2016.

[19] N. Zhang and H. Xia, "Dynamic analysis of coupled vehiclebridge system based on inter-system iteration method," Computers \& Structures, vol. 114-115, pp. 26-34, 2013.

[20] N. Zhang, H. Xia, and W. W. Guo, "Vehicle-bridge interaction analysis under high-speed trains," Journal of Sound and Vibration, vol. 309, no. 3-5, pp. 407-425, 2008.

[21] S. G. M. Neves, P. A. Montenegro, A. F. M. Azevedo et al., "An algorithm for dynamic vehicle-track-structure interaction analysis for high-speed trains," Engineering Structures, vol. 69, pp. 83-89, 2014.

[22] P. Antolín, N. Zhang, J. M. Goicolea, H. Xia, M. Á. Astiz, and J. Oliva, "Consideration of nonlinear wheel-rail contact forces for dynamic vehicle-bridge interaction in high-speed railways," Journal of Sound and Vibration, vol. 332, no. 5, pp. 1231-1251, 2013.

[23] J. Pombo and J. Ambrósio, "An alternative method to include track irregularities in railway vehicle dynamic analyses," Nonlinear Dynamics, vol. 68, no. 1-2, pp. 161-176, 2012.

[24] V. N. Dinh, K. D. Kim, and P. Warnitchai, "Dynamic analysis of three-dimensional bridge-high-speed train interactions using a wheel-rail contact model," Engineering Structures, vol. 31, no. 12, pp. 3090-3106, 2009.

[25] Z.-W. Yu and J.-F. Mao, "Probability analysis of train-trackbridge interactions using a random wheel/rail contact model," Engineering Structures, vol. 144, pp. 120-138, 2017. 
[26] H. Li, H. Xia, M. Soliman, and D. M. Frangopol, "Bridge stress calculation based on the dynamic response of coupled trainbridge system," Engineering Structures, vol. 99, pp. 334-345, 2015.

[27] P. Galvín, A. Romero, E. Moliner, and M. D. MartínezRodrigo, "Two FE models to analyse the dynamic response of short span simply-supported oblique high-speed railway bridges: comparison and experimental validation," Engineering Structures, vol. 167, pp. 48-64, 2018.

[28] H. Y. Gou, W. Zhou, Y. Bao, X. Li, and Q. Pu, "Experimental study on dynamic effects of a long-span railway continuous beam bridge," Applied Sciences, vol. 8, no. 5, Article ID 8050669, 17 pages, 2018.

[29] X. J. Zhang, X. L. Jin, and X. D. Chen, "Simulation of the interactions between a train and a long-span cable-stayed bridge using parallel computing with domain decomposition," Proceedings of the Institution of Mechanical Engineers, Part F: Journal of Rail and Rapid Transit, vol. 226, no. 4, pp. 347-359, 2011.

[30] W. M. Zhai, H. Xia, C. Cai et al., "High-speed train-trackbridge dynamic interactions-part I: theoretical model and numerical simulation," International Journal of Rail Transportation, vol. 1, no. 1-2, pp. 3-24, 2013.

[31] Dassault Systémes Simulia Corporation, Abaqus Analysis User's Manual 6.12, Dassault Systémes Simulia Corporation, Providence, RI, USA, 2012.

[32] C. Y. Chang, C. G. Wang, and Y. Jin, "Numerical analysis of wheel- rail wear based on 3D dynamic finite element mode," China Railway Science, vol. 29, no. 4, pp. 89-95, 2008.

[33] W. M. Zhai and H. Xia, Train-Track-Bridge Dynamic Interactions: Theory and Engineering Application, Science Press, Beijing, China, 2011. 